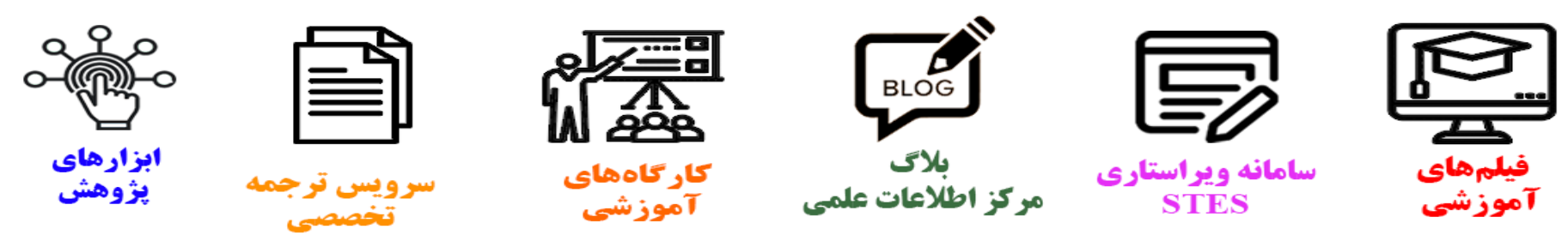

\title{
(c)
}

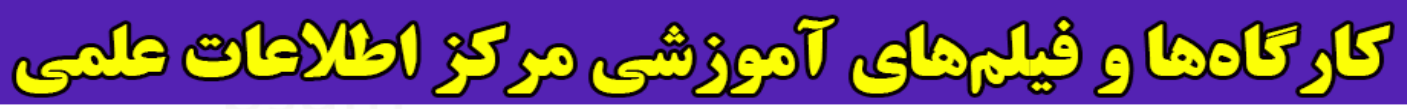
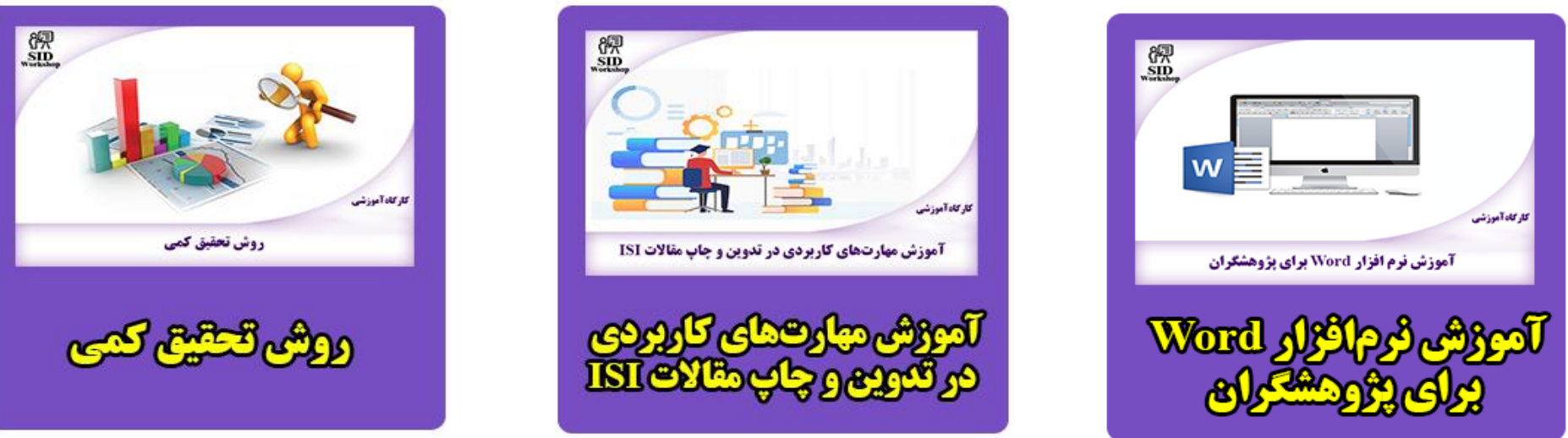


\title{
International Journal of Engineering
}

Journal Hom e page: ww w. i je.ir

\section{Experimental Investigation of Force Convection Heat Transfer in a Car Radiator Filled with $\mathrm{SiO}_{2}$-water Nanofluid}

\author{
M. Ebrahimi*, M. Farhadi, K. Sedighi, S. Akbarzade \\ Department of Mechanical Engineering, Babol University of Technology, Babol, Iran
}

\section{$P A P E R \quad I N F O$}

Paper history:

Received 23 May 2013

Received in revised form 09 August 2013

Accepted 22 August 2013

Keywords:
Nanofluid
Experimental Procedure
Heat Exchanger
Radiator
Nusselt Number

Nusselt Number

\section{$A B S T R A C A$}

In this study, effect of adding $\mathrm{SiO}_{2}$ nanoparticle to base fluid (water) in car radiator is investigated experimentally. Radiators are compact heat exchangers optimized and evaluated by considering different working conditions. The cooling system of a car plays an important role in vehicle's performance, consists of two main parts, known as radiator and fan. Improving thermal efficiency of engine leads to increase the engine's performance, decline the fuel consumption and decrease the pollution emissions. For this purpose, an experimental setup was designed. Effects of fluid inlet temperature, the flow rate and nano particle volume fraction on heat transfer are considered. Results show that Nusselt number increases with increase of liquid inlet temperature, nano particle volume fraction and Reynolds number.

doi: 10.5829/idosi.ije.2014.27.02b.17

\begin{tabular}{|c|c|c|c|}
\hline \multicolumn{4}{|c|}{ Nomenclature } \\
\hline$A$ & peripheral area $\left(\mathrm{m}^{2}\right)$ & \multicolumn{2}{|c|}{ Greek letters } \\
\hline$c_{p}$ & specific heat $(\mathrm{J} / \mathrm{kg} \mathrm{K})$ & $\rho$ & density $\left(\mathrm{kg} / \mathrm{m}^{3}\right)$ \\
\hline$f$ & Friction factor & $\mu$ & viscosity $(\mathrm{kg} / \mathrm{m} \mathrm{s})$ \\
\hline$d_{h y}$ & hydraulic diameter $(\mathrm{m})=(4 \mathrm{~A} / \mathrm{P})$ & $\phi$ & volume fraction \\
\hline$h$ & heat transfer coefficient $\left(\mathrm{W} / \mathrm{m}^{2} \mathrm{~K}\right)$ & \multicolumn{2}{|c|}{ Subscripts } \\
\hline$k$ & thermal conductivity $(\mathrm{W} / \mathrm{m} \mathrm{K})$ & $b$ & bulk \\
\hline$m$ & mass flow rate $(\mathrm{kg} / \mathrm{s})$ & $f$ & Base fluid \\
\hline $\mathrm{Nu}$ & average Nusselt number & in & input \\
\hline $\operatorname{Pr}$ & Prandtl number $\left(=\mu_{f} /\left(\rho_{f} \alpha_{f}\right)\right)$ & $n f$ & nanofluid \\
\hline $\operatorname{Re}$ & Reynolds number $=4 \dot{m} /\left(\pi d_{h y} \mu\right)$ & out & output \\
\hline \multirow[t]{2}{*}{$T$} & temperature & $p$ & particle \\
\hline & & $W$ & Wall \\
\hline
\end{tabular}

\section{INTRODUCTION}

The radiator is an important accessory of vehicle engine. Normally, it is used as a cooling system of the engine and generally water is the heat transfer medium. For this liquid-cooled system, the waste heat is removed

*Corresponding Author Email: m.ebrahimi1987@yahoo.com (M. Ebrahimi) via the circulating coolant surrounding the devices or entering the cooling channels in devices. The coolant is propelled by pumps and the heat is carried away mainly by heat exchangers. Optimal mass characteristics for a heat pipe radiator assembly for space application were investigated by Vlassov et al. [1]. Their results showed that under certain combinations of input parameters, the assembly with acetone HP can be more weight effective 
than the one with ammonia, in spite of the liquid transport factor criterion indicates an opposite trend. Pantzali et al. [2] investigated the efficacy of nanofluids as coolants in heat exchangers. They concluded that in industrial heat exchangers, where large volumes of nanofluids are necessary and turbulent flow is usually developed, the substitution of conventional fluids by nanofluids seems inauspicious.

Nowadays, high prices of energy motivate industries to apply energy saving methods as much as possible in their facilities. Common heat transfer fluids such as water, ethylene glycol, and engine oil have limited heat transfer capabilities due to their low heat transfer properties. In contrast, the thermal conductivity of most metals are up to three times higher than the fluids. Therefore, it is naturally desirable to combine the two substances to produce a heat transfer medium that behaves like a fluid, but has the thermal conductivity of a metal. The term 'nanofluid' is envisioned to describe a fluid in which nanometer-sized particles are suspended in conventional heat transfer basic fluids [3]. Leong et al. [4] attempted to investigate the heat transfer characteristics of an automotive car radiator using ethylene glycol based copper nanofluids numerically. Thermal performance of an automotive car radiator operated with nanofluids has been compared with a radiator using conventional coolants. Naraki et al. [5] investigated the overall heat transfer coefficient of $\mathrm{CuO} /$ water nanofluids under laminar flow regime in a car radiator. They showed that the overall heat transfer coefficient decreases with increasing inlet temperature of the nanofluid. Vajjha et al. [6] have numerically studied a three-dimensional laminar flow and heat transfer with two different nanofluids, $\mathrm{Al}_{2} \mathrm{O}_{3}$ and $\mathrm{CuO}$, in the ethylene glycol/water mixture circulating through the flat tubes of an automobile radiator to evaluate their superiority over the base fluid. Convective heat transfer coefficient in the developing and developed regions along the flat tubes with the nanofluid flow showed considerable improvement over the base fluid. Lai et al. [7] studied the flow behavior of nanofluids $\left(\mathrm{Al}_{2} \mathrm{O}_{3}\right.$ water; $20 \mathrm{~nm}$ ) in a millimeter-sized stainless steel test tube, subjected to constant wall heat flux and a low Reynolds number $(\operatorname{Re}<270)$. The maximum Nusselt number enhancement of the nanofluid of $8 \%$ at the concentration of 1 vol. $\%$ was recorded. Peyghambarzadeh et al. [8] studied forced convection heat transfer in a car radiator using water/ethylene glycol based nanofluids. They found that about $40 \%$ heat transfer enhancement can be obtained compared to the base fluids. Jung et al. [9] conducted convective heat transfer experiments for a nanofluid $\left(\mathrm{Al}_{2} \mathrm{O}_{3}\right.$-water $)$ in a rectangular microchannel under laminar flow conditions. The convective heat transfer coefficient increased by more than $32 \%$ form 1.8 vol. $\%$ nanoparticle in the base fluids. The Nusselt number increased with an increasing Reynolds number in the laminar flow regime $(5<\operatorname{Re}<300)$ and a new convective heat transfer correlation for nanofluids in microchannels was also proposed. Peyghambarzadeh et al. [10] studied the heat transfer of coolant flow through the automobile radiators as it is of great importance for the optimization of fuel consumption. They indicated that increasing the nanoparticle concentration, air velocity, and nanofluid velocity enhances the overall heat transfer coefficient. Kim et al. [11] investigated the effect of nanofluids on the performances of convective heat transfer coefficient of a circular straight tube having laminar and turbulent flow with constant heat flux. Authors have found that the convective heat transfer coefficient of alumina nanofluids is improved in comparison to base fluid by $15 \%$ and $20 \%$ in laminar and turbulent flows, respectively. Squeezing unsteady nanofluid flow and heat transfer has been studied by Sheikholeslami et al. [12]. They showed that for the case in which two plates are moving together, the Nusselt number increases with increase of nanoparticle volume fraction and Eckert number, while it decreases with growth of the squeeze number. Zamzamian et al. [13] investigated experimentally the forced convective heat transfer coefficient in $\mathrm{Al}_{2} \mathrm{O}_{3} / \mathrm{EG}$ and $\mathrm{CuO} / \mathrm{EG}$ nanofluids in a double pipe and plate heat exchangers under turbulent flow. Their findings indicated considerable enhancement in convective heat transfer coefficient of the nanofluids as compared with the base fluid, ranging from 2 to $50 \%$. Recently, several studies about nanofluid effect on heat transfer enhancement have been published [14-29].

In this paper, forced convection heat transfer coefficients are reported for pure water and water $/ \mathrm{SiO}_{2}$ nano powder mixtures. The test section is made up with a typical automobile radiator, and the effects of the inlet temperature and nano particle volume fraction on heat transfer enhancement are examined.

\section{EXPERIMENTAL RIG}

Figure 1 depicts a schematic of the experimental apparatus employed in the present study. The mixture flows in a closed loop consisting of flow lines, two storage tanks, two heaters, a centrifugal pump, a flow meter, a forced draft fan and a cross flow heat exchanger (an automobile radiator). For cooling the liquid, a forced fan (Techno Pars $2080 \mathrm{rpm}$ ) was used. A flow meter (Technical Group LZM-15Z Type) was used to control and manipulate the flow rate with the precision of $0.2 \mathrm{l} / \mathrm{min}$. Figure 2 shows the applied automobile radiator in test set up. The characteristics of radiator are illustrated in Table 1 [30]. The working fluid fills $25 \%$ of the storage tank whose total volume is 301 (height of $35 \mathrm{~cm}$ and diameter of $30 \mathrm{~cm}$ ). Two Ktype thermocouples (DLS 1) were implemented on the flow line to record radiator fluid inlet and outlet 
temperatures. Also, four other thermocouples were used for radiator wall temperature measurement. These thermocouples were installed at the center of the radiator surfaces (both sides). Due to very small thickness and very high thermal conductivity of the flat tubes, it is reasonable to equate the inside temperature of the tube with the outside one.

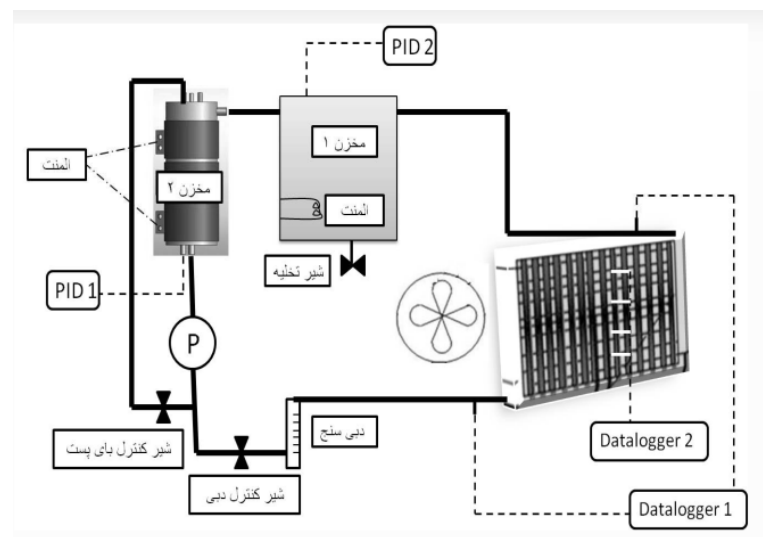

(a)

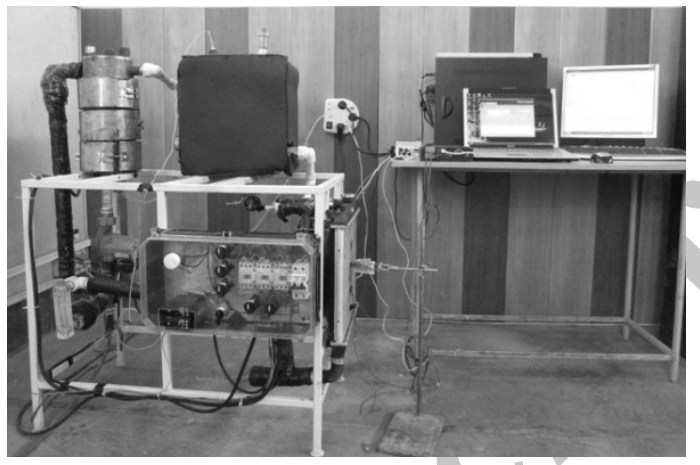

(b)

Figure 1. (a) Schematic of experimental setup; (b) Experimental setup.

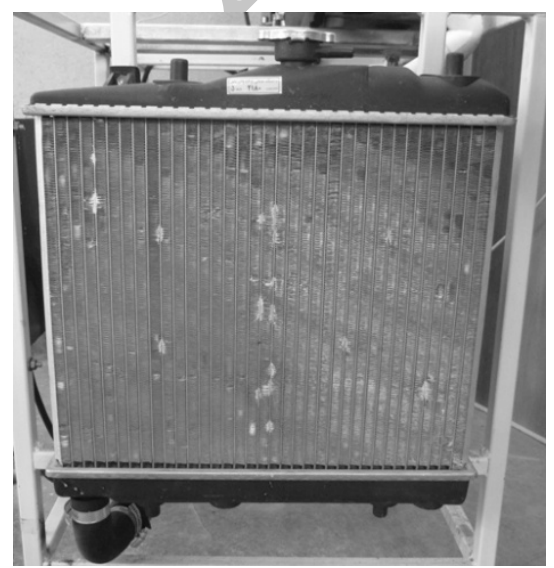

Figure 2. The applied automobile radiator.
TABLE 1.The characteristics of radiator are illustrated [30].

\begin{tabular}{lc}
\hline Type of fin and tubes & Aluminum \\
\hline Dimensions of the radiator & $320 \times 20 \times 382.4 \mathrm{~mm}$ \\
Fin shape & Corrugated \\
Heat transfer area & $1.25 \mathrm{~m}^{2}$ \\
Side area & $4.7 \mathrm{~m}^{2}$ \\
Volume of the fin & 1.14 litre \\
\hline
\end{tabular}

\section{NANOFLUID PROPERTIES}

By assuming that the nanoparticles are well dispersed within the base fluid, i.e. the particle concentration can be considered uniform throughout the system; the effective physical properties of the studied mixtures can be evaluated using some classical formulas as usually used for two phase fluids. These relations have been used to predict nanofluid physical properties like density, specific heat, viscosity and thermal conductivity at different temperatures and concentrations [14]. In this paper, the following correlations were used to calculate these physical properties of nanofluid:

$(\rho)_{n f}=(1-\phi) \rho_{f}+\phi \rho_{p}$

$C_{p_{n f}}=\frac{(1-\phi)\left(\rho C_{p}\right)_{f}+\phi\left(\rho C_{p}\right)_{p}}{\rho_{n f}}$

$\mu_{n f}=\mu_{f}(1+2.5 \phi)$

$\frac{k_{n f}}{k_{f}}=\frac{k_{p}+2 k_{f}+2\left(k_{p}-k_{f}\right) \phi_{e f f}}{k_{p}+2 k_{f}-\left(k_{p}-k_{f}\right) \phi_{e f f}}$

In the above equations, the subscripts " $p$ ", " $\mathrm{f}$ " and "nf" refer to the particles, water, and nanofluid respectively. The characteristics of water and $\mathrm{SiO}_{2}$ nanoparticles at room temperature are summarized in Table 2.

To obtain heat transfer coefficient and corresponding Nusselt number, the following procedure has been performed. According to Newton's cooling law:

$Q=h A \Delta T=h A\left(T_{b}-T_{w}\right)$

Heat transfer rate can be calculated as follows:

$Q=m c_{p} \Delta T=m c_{p}\left(T_{\text {in }}-T_{\text {out }}\right)$

Regarding the equality of $\mathrm{Q}$ in the above equations:

$N u=\frac{h_{\text {exp }} \mathrm{d}_{h y}}{k}=\frac{m c_{p}\left(T_{\text {in }}-T_{\text {out }}\right) \mathrm{d}_{h y}}{A\left(T_{b}-T_{w}\right) \mathrm{k}}$

In Equation (7), $\mathrm{Nu}$ is average Nusselt number for the whole radiator, $\mathrm{m}$ mass flow rate which is the product of density and volume flow rate of fluid, $c_{p}$ fluid specific heat capacity, and $T_{\text {in }}$ and $T_{\text {out }}$ inlet and outlet 
temperatures, $T_{b}$ bulk temperature which was assumed to be the average values of inlet and outlet temperature of the fluid moving through the radiator, and $T_{W}$ tube wall temperature which is the mean value by two surface thermocouples. In this equation, $k$ is thermal conductivity of the fluid and $d_{h y}$ is hydraulic diameter of the tube. It should also be mentioned that all the physical properties were calculated at fluid bulk temperature. The temperatures measured by these thermocouples were shown on three digital monitors with the accuracy of $0.01^{\circ} \mathrm{C}$ and the accuracy of inlet and outlet temperature was estimated to be $\pm 0.5^{\circ} \mathrm{C}$.

\section{RESULT AND DISSCUSION}

Before conducting systematic experiments on the application of nanofluids in the radiator, some experimental runs with pure water and waterpropyleneglicol were carried out in order to check the reliability and accuracy of the experimental setup. Comparison was made between the experimental data and two well-known empirical correlations: one of them suggested by Gnielinsky [31] and the other developed by Petukhov et al. [32] (see Figures 3 and 4). These two relations are shown in Equations (8) and (11), respectively. In Equation (9), fis friction factor.

$$
\overline{N u}=\frac{\left(\frac{f}{2}\right)(\operatorname{Re}-1000) \operatorname{Pr}}{1+12.7\left(\frac{f}{2}\right)^{0.5}\left(\operatorname{Pr}^{\frac{2}{3}}-1\right)},
$$

$2300<\operatorname{Re}<5 \times 10^{6}, 0.5<\operatorname{Pr}<2000$

$$
f=(1.58 \ln (\operatorname{Re})-3.82)^{-2}
$$

$$
\overline{N u}=\frac{\left(\frac{f}{8}\right) \operatorname{Re} \cdot \operatorname{Pr}}{1.07+12.7\left(\frac{f}{8}\right)^{0.5}\left(\operatorname{Pr}^{\frac{2}{3}}-1\right)},
$$

$3 \times 10^{3}<\operatorname{Re}<5 \times 10^{6}, 0.5<\operatorname{Pr}<2000$

$$
f=(1.82 \log (\operatorname{Re})-1.64)^{-2}
$$

Also, present study was compared with that of Peyghambarzadeh et al. [33] (Figure 3). All of these results show good agreements. Figure 5 shows the effects of the Reynolds number, nanoparticle volume fraction and fluid inlet temperature on Nusselt number. The velocity components of nanofluid increase as a result of an increase in the energy transport in the fluid with the increasing the volume fraction. The sensitivity of thermal boundary layer thickness to volume fraction of nanoparticles is related to the increased thermal conductivity of the nanofluid. In fact, higher values of thermal conductivity are accompanied by higher values of thermal diffusivity.

The high value of thermal diffusivity causes a drop in the temperature gradients and accordingly increases the boundary thickness. This increase in thermal boundary layer thickness reduces the Nusselt number, however, the Nusselt number is a multiplication of temperature gradient and the thermal conductivity ratio (conductivity of the of the nanofluid to the conductivity of the base fluid).

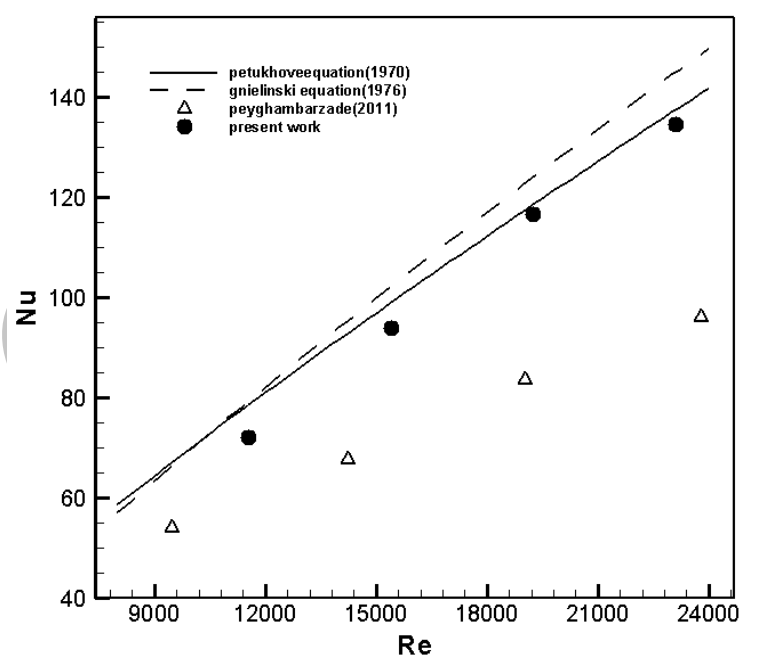

Figure 3. Comparison between results obtained in previous studied and present study for pure water

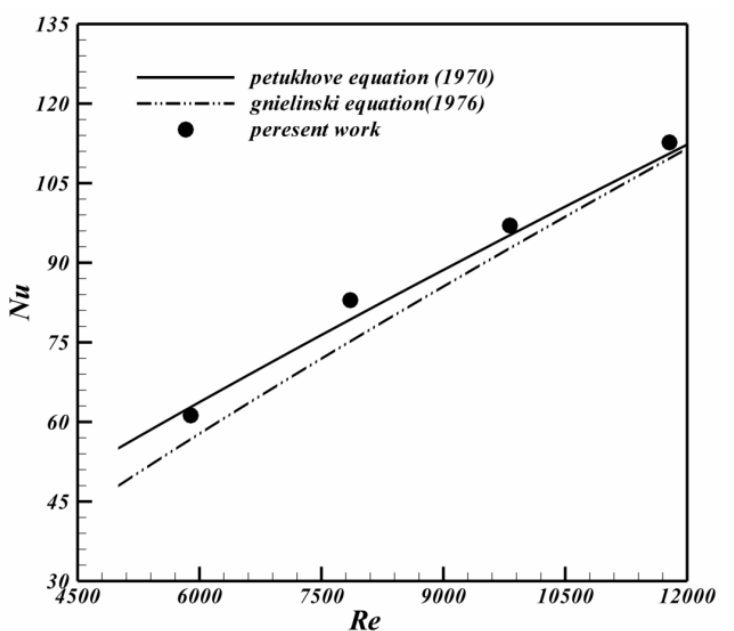

Figure 4. Comparison between results obtained in previous studied and present study for water-propilenglicol. 


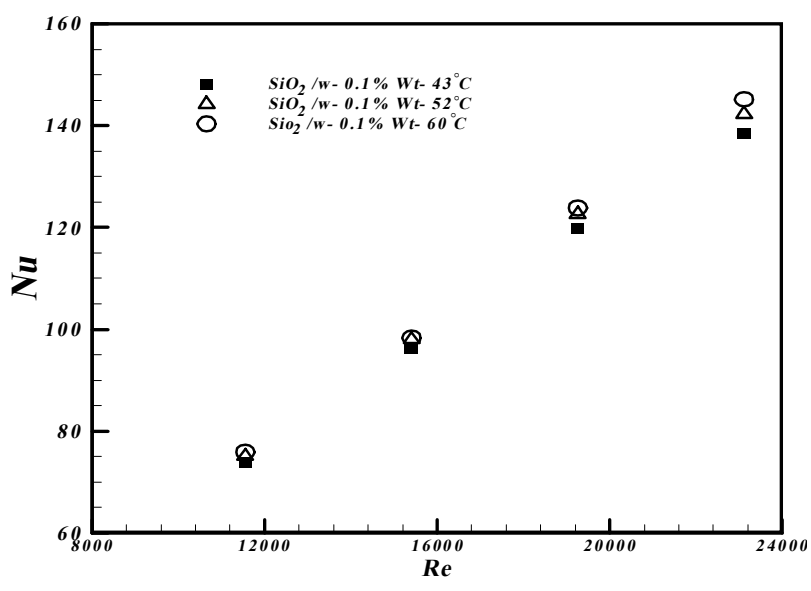

(a)

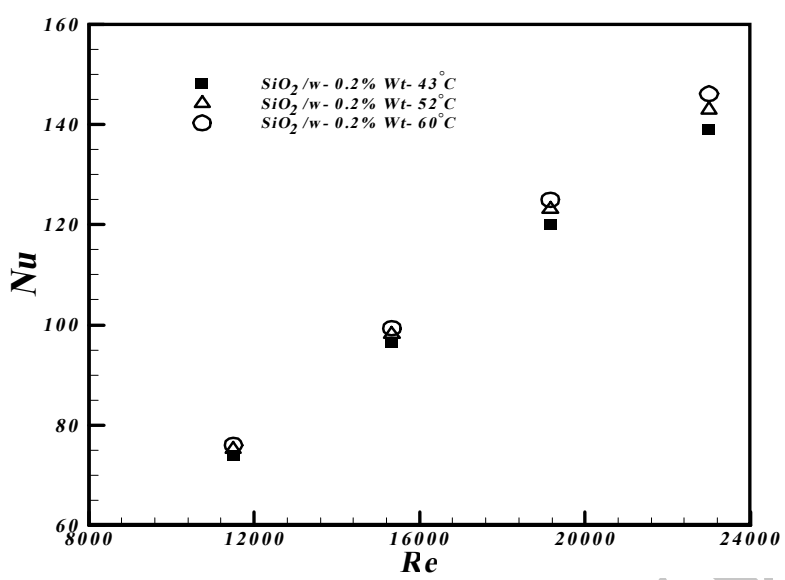

(b)

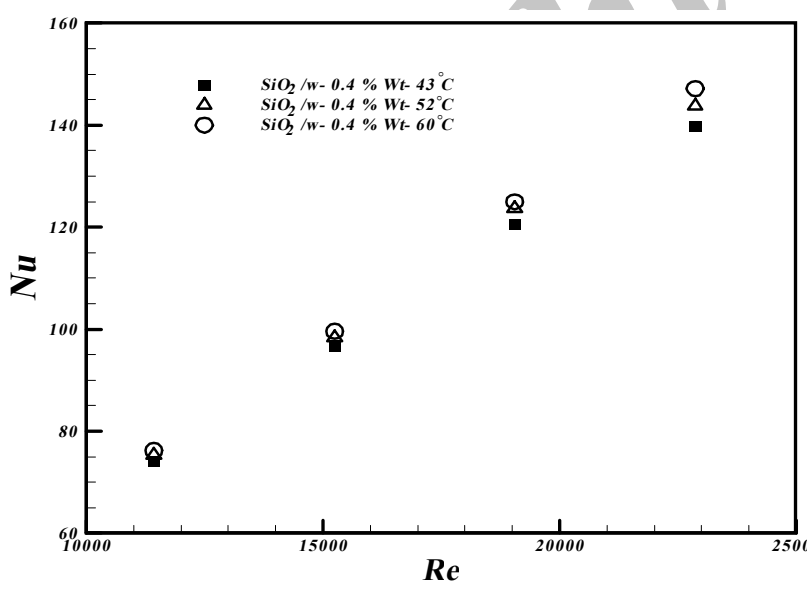

(c)

Figure 5. Effects of the Reynolds number, nanoparticle volume fraction and fluid inlet temperature on Nusselt number.

Since the reduction in temperature gradient due to the presence of nanoparticles is much smaller than thermal conductivity ratio, therefore, an enhancement in
Nusselt number is taking taken place by increasing the volume fraction of nanoparticles. Therefore, addition of nanoparticles to the coolant has the potential to improve automotive and heavy-duty engine cooling rates, or equally causes to remove the engine heat with a reduced-size cooling system. In order to consider the effect of temperature on thermal performance of the radiator, different fluid inlet temperatures have been applied for each concentration. The fluid inlet temperatures include $43^{\circ} \mathrm{C}, 52^{\circ} \mathrm{C}$, and $60^{\circ} \mathrm{C}$ for the water based $\mathrm{SiO}_{2}$ nanofluid. This figure shows that an increase in the fluid inlet temperature slightly enhances Nusselt number because of augmentation in the effect of test liquid radiation to the internal wall of the tubes.

Also, this figure shows that Nusselt number increases with increase of Reynolds number. The enhancement of heat transfer between the case of nanofluid and the pure fluid (base fluid) case is defined as:

$E=\frac{N u(\phi)-N u(\text { basefluid })}{N u(\text { basefluid })} \times 100$

Effects of the Reynolds number, nanoparticle volume fraction and fluid inlet temperature on enhancement in heat transfer are shown in Figure 6. As can be seen, the enhancement in heat transfer has increased by augmentation in the concentrations of nanoparticle, constant Reynolds number and fluid inlet temperature. For the water based nanofluid it is obvious that $E$ increases with Reynolds number and in higher concentrations of nanoparticle the effect of Reynolds number becomes pronounced. Improvement in the heat transfer rate when $\phi=0.04$ and water considered as base fluid is about $3.8 \%$, and this value is about $4 \%$ for water-propilenglicol.

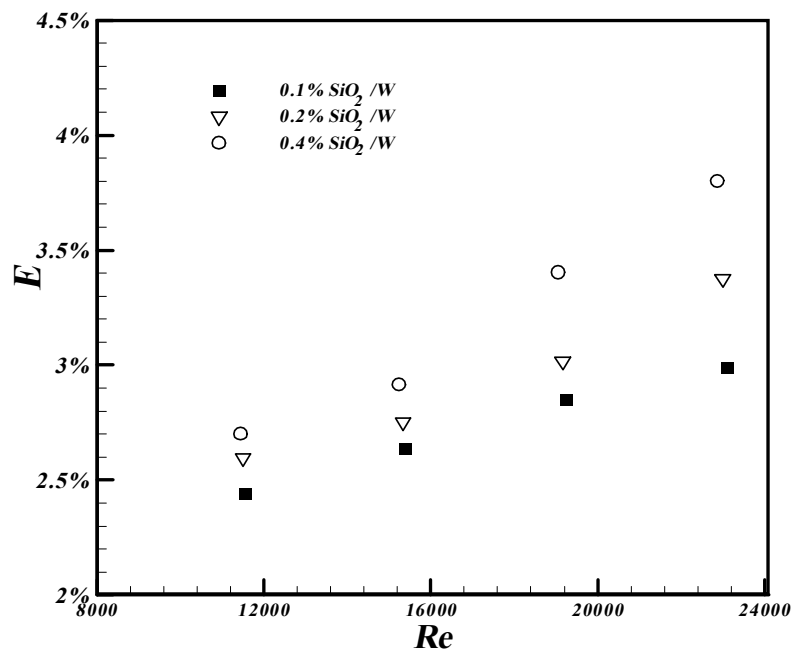

(a) 


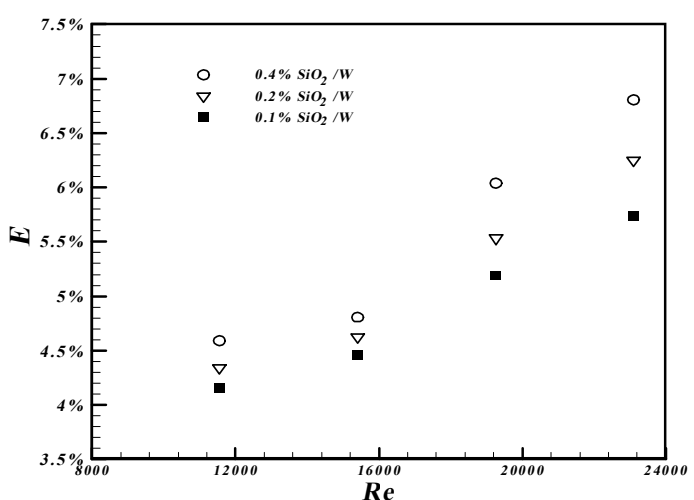

(b)

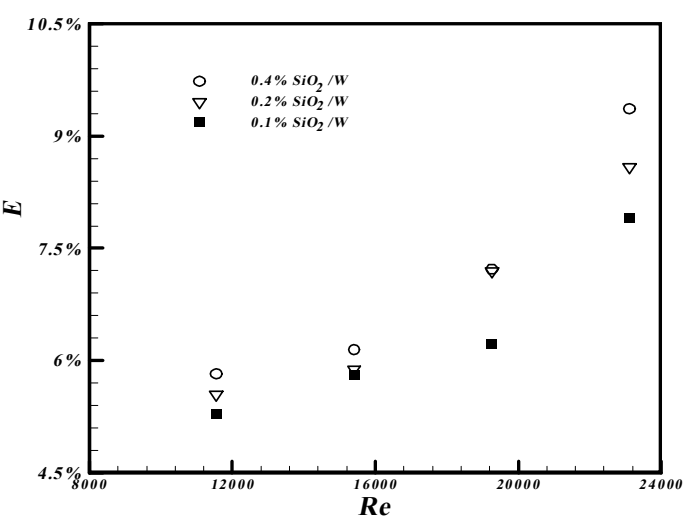

(c)

Figure 6. Effects of the Reynolds number, nanoparticle volume fraction and fluid inlet temperature on enhancement in heat transfer when (a) $T_{i n}=43^{\circ} \mathrm{C}$; (b) $T_{i n}=52^{\circ} \mathrm{C}$; (c) $T_{\text {in }}=60^{\circ} \mathrm{C}$.

\section{CONCLUSION}

In this paper, the convective heat transfer enhancement of $\mathrm{SiO}_{2}$-water nanofluid as the coolants inside aluminum tubes of the car radiator has been investigated. The correlation developed by Gnielinsky et al. and Petukhov et al. predicts well the experimental data. Effects of fluid inlet temperature, Reynolds number and nanoparticle volume fraction on heat transfer are considered. Using nanofluid as working fluid leads to higher heat transfer performance which is promoted the car engine performance and would reduce fuel consumption. Nusselt number increases with increase of liquid inlet temperature, nanoparticle volume fraction and Reynolds number.

\section{REFERENCES}

1. Vlassov, V. V., de Sousa, F. L. and Takahashi, W. K., "Comprehensive optimization of a heat pipe radiator assembly filled with ammonia or acetone", International Journal of Heat and Mass Transfer, Vol. 49, No. 23, (2006), 4584-4595.
2. Pantzali, M., Mouza, A. and Paras, S., "Investigating the efficacy of nanofluids as coolants in plate heat exchangers (PHE)", Chemical Engineering Science, Vol. 64, No. 14, (2009), 3290-3300.

3. Kakaç, S. and Pramuanjaroenkij, A., "Review of convective heat transfer enhancement with nanofluids", International Journal of Heat and Mass Transfer, Vol. 52, No. 13, (2009), 31873196.

4. Leong, K., Saidur, R., Kazi, S. and Mamun, A., "Performance investigation of an automotive car radiator operated with nanofluid-based coolants (nanofluid as a coolant in a radiator)", Applied Thermal Engineering, Vol. 30, No. 17, (2010), 26852692.

5. Naraki, M., Peyghambarzadeh, S., Hashemabadi, S. and Vermahmoudi, Y., "Parametric study of overall heat transfer coefficient of cuo/water nanofluids in a car radiator", International Journal of Thermal Sciences, (2013).

6. Vajjha, R. S., Das, D. K. and Namburu, P. K., "Numerical study of fluid dynamic and heat transfer performance of $\mathrm{Al}_{2} \mathrm{O}_{3}$ and cuo nanofluids in the flat tubes of a radiator", International Journal of Heat and Fluid Flow, Vol. 31, No. 4, (2010), 613-621.

7. Lai, W., Duculescu, B., Phelan, P. and Prasher, R., "Convective heat transfer with nanofluids in a single 1.02-mm tube", ASME. (2006).

8. Peyghambarzadeh, S., Hashemabadi, S., Hoseini, S. and Seifi Jamnani, M., "Experimental study of heat transfer enhancement using water/ethylene glycol based nanofluids as a new coolant for car radiators", International Communications in Heat and Mass Transfer, Vol. 38, No. 9, (2011), 1283-1290.

9. Jung, J.-Y., Oh, H.-S. and Kwak, H.-Y., "Forced convective heat transfer of nanofluids in microchannels", International Journal of Heat and Mass Transfer, Vol. 52, No. 1, (2009), 466-472.

10. Peyghambarzadeh, S., Hashemabadi, S., Naraki, M. and Vermahmoudi, Y., "Experimental study of overall heat transfer coefficient in the application of dilute nanofluids in the car radiator", Applied Thermal Engineering, (2012).

11. Kim, D., Kwon, Y., Cho, Y., Li, C., Cheong, S., Hwang, Y., Lee, J., Hong, D., and Moon, S., "Convective heat transfer characteristics of nanofluids under laminar and turbulent flow conditions", Current Applied Physics, Vol. 9, No. 2, (2009), e119-e123.

12. Sheikholeslami, M., Ganji, D. and Ashorynejad, H., "Investigation of squeezing unsteady nanofluid flow using adm", Powder Technology, (2013).

13. Zamzamian, A., Oskouie, S. N., Doosthoseini, A., Joneidi, A. and Pazouki, M., "Experimental investigation of forced convective heat transfer coefficient in nanofluids of $\mathrm{Al}_{2} \mathrm{O}_{3} / \mathrm{eg}$ and cuo/eg in a double pipe and plate heat exchangers under turbulent flow", Experimental Thermal and Fluid Science, Vol. 35, (2011), 495-502.

14. Khanafer, K., Vafai, K. and Lightstone, M., "Buoyancy-driven heat transfer enhancement in a two-dimensional enclosure utilizing nanofluids", International Journal of Heat and Mass Transfer, Vol. 46, No. 19, (2003), 3639-3653.

15. Sheikholeslami, M., Gorji-Bandpy, M. and Ganji, D., "Natural convection in a nanofluid filled concentric annulus between an outer square cylinder and an inner elliptic cylinder", Scientia Iranica Transactions B: Mechanical Engineering, Vol. 20, (2013), 1241-1253.

16. Sheikholeslami, M., Ganji, D. and Rokni, H., "Nanofluid flow in a semi-porous channel in the presence of uniform magnetic field", International Journal of Engineering-Transactions C: Aspects, Vol. 26, No. 6, (2013), 653.

17. Avramenko, A., Blinov, D. and Shevchuk, I., "Self-similar analysis of fluid flow and heat-mass transfer of nanofluids in boundary layer", Physics of Fluids, Vol. 23, (2011), 082002. 
18. Sheikholeslami, M., Gorji-Bandpay, M. and Ganji, D., "Magnetic field effects on natural convection around a horizontal circular cylinder inside a square enclosure filled with nanofluid", International Communications in Heat and Mass Transfer, Vol. 39, No. 7, (2012), 978-986.

19. Sheikholeslami, M., Gorji-Bandpy, M., Pop, I. and Soleimani, S., "Numerical study of natural convection between a circular enclosure and a sinusoidal cylinder using control volume based finite element method", International Journal of Thermal Sciences, Vol. 72, No., (2013), 147-158.

20. Sheikholeslami, M., Hatami, M. and Ganji, D., "Analytical investigation of mhd nanofluid flow in a semi-porous channel", Powder Technology, (2013).

21. Sheikholeslami, M., Gorji-Bandpy, M., Ganji, D. and Soleimani, S., "Natural convection heat transfer in a cavity with sinusoidal wall filled with cuo-water nanofluid in presence of magnetic field", Journal of the Taiwan Institute of Chemical Engineers, (2013).

22. Sheikholeslami, M., Gorji-Bandpy, M., Ganji, D. and Soleimani, S., "Effect of a magnetic field on natural convection in an inclined half-annulus enclosure filled with $\mathrm{cu}-$ water nanofluid using cvfem", Advanced Powder Technology, (2013).

23. Sheikholeslami, M., Gorji-Bandpy, M. and Soleimani, S., "Two phase simulation of nanofluid flow and heat transfer using heatline analysis", International Communications in Heat and Mass Transfer, Vol. 47, (2013), 73-81.

24. Sheikholeslami, M., Gorji Bandpy, M., Ellahi, R., Hassan, M. and Soleimani, S., "Effects of mhd on cu-water nanofluid flow and heat transfer by means of cvfem", Journal of Magnetism and Magnetic Materials, Vol. 349, (2014), 188-200.

25. Kayhani, M. H., Soltanzadeh, H., Heyhat, M. M., Nazari, M. and Kowsary, F., "Experimental study of convective heat transfer and pressure drop of $\mathrm{TiO}_{2}$ /water nanofluid", International
Communications in Heat and Mass Transfer, Vol. 39, No. 3, (2012), 456-462.

26. Maghrebi, M. J., Nazari, M. and Armaghani, T., "Forced convection heat transfer of nanofluids in a porous channel", Transport in Porous Media, Vol. 93, No. 3, (2012), 401-413.

27. Kayhani, M. H., Nazari, M., Soltanzadeh, H., Heyhat, M. M. and Kowsary, F., "Experimental analysis of turbulent convective heat transfer and pressure drop of $\mathrm{Al}_{2} \mathrm{O}_{3}$ /water nanofluid in horizontal tube", Micro \& Nano Letters IET, Vol. 7, No. 3, (2012), 223-227.

28. Heyhat, M. M., Kowsary, F., Rashidi, A. M., Momenpour, M. H. and Amrollahi, A., "Experimental investigation of laminar convective heat transfer and pressure drop of water-based $\mathrm{Al}_{2} \mathrm{O}_{3}$ nanofluids in fully developed flow regime", Experimental Thermal and Fluid Science, Vol. 44, (2013), 483-489.

29. Heyhat, M., Kowsary, F., Rashidi, A., Alem Varzane Esfehani, S. and Amrollahi, A., "Experimental investigation of turbulent flow and convective heat transfer characteristics of alumina water nanofluids in fully developed flow regime", International Communications in Heat and Mass Transfer, (2012).

30. Saidi, M., "Experimental prediction of nusselt number and coolant heat transfer coefficient in compact heat exchanger performed with E-NTU method", Engine Research, (2010).

31. Gnielinski, V., "New equations for heat and mass transfer in the turbulent flow in pipes and channels", NASA STI/Recon Technical Report A, Vol. 75, (1975), 22028.

32. Petukhov, B., "Heat transfer and friction in turbulent pipe flow with variable physical properties", Advances in heat transfer, Vol. 6, (1970), 503-564.

33. Peyghambarzadeh, S. M., Hashemabadi, S. H., Seifi Jamnani, M. and Hoseini, S. M., "'Improving the cooling performance of automobile radiator with $\mathrm{Al}_{2} \mathrm{O}_{3}$ /water ", Applied Thermal Engineering, Vol. 31, No. 10, (2011), 1833-1838. 


\title{
Experimental Investigation of Force Convection Heat Transfer in a Car Radiator Filled with $\mathrm{SiO}_{2}$-water Nanofluid
}

\author{
M. Ebrahimi, M. Farhadi, K. Sedighi, S. Akbarzade
}

Department of Mechanical Engineering, Babol University of Technology, Babol, Iran

PAPER INFO

جكيده

Paper history:

Received 23 May 2013

Received in revised form 09 August 2013

Accepted 22 August 2013

\section{Keywords:}

Nanofluid

Experimental Procedure

Heat Exchanger

Radiator

Nusselt Number

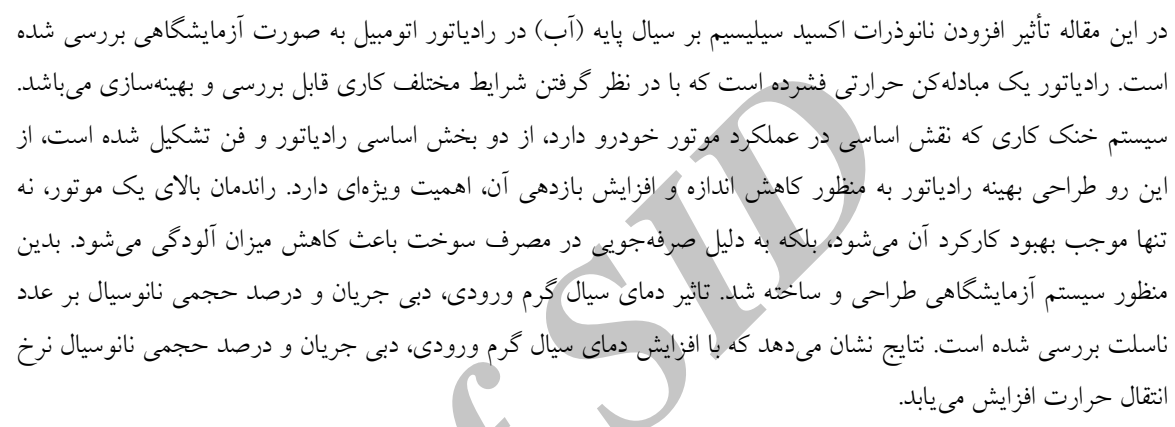




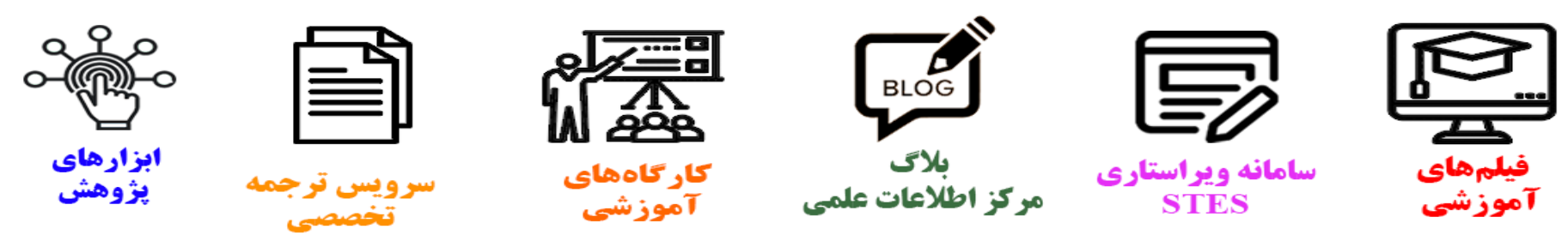

\section{(c)}

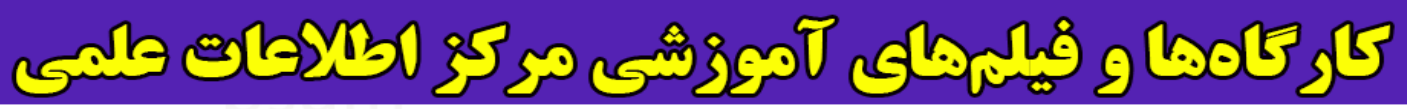
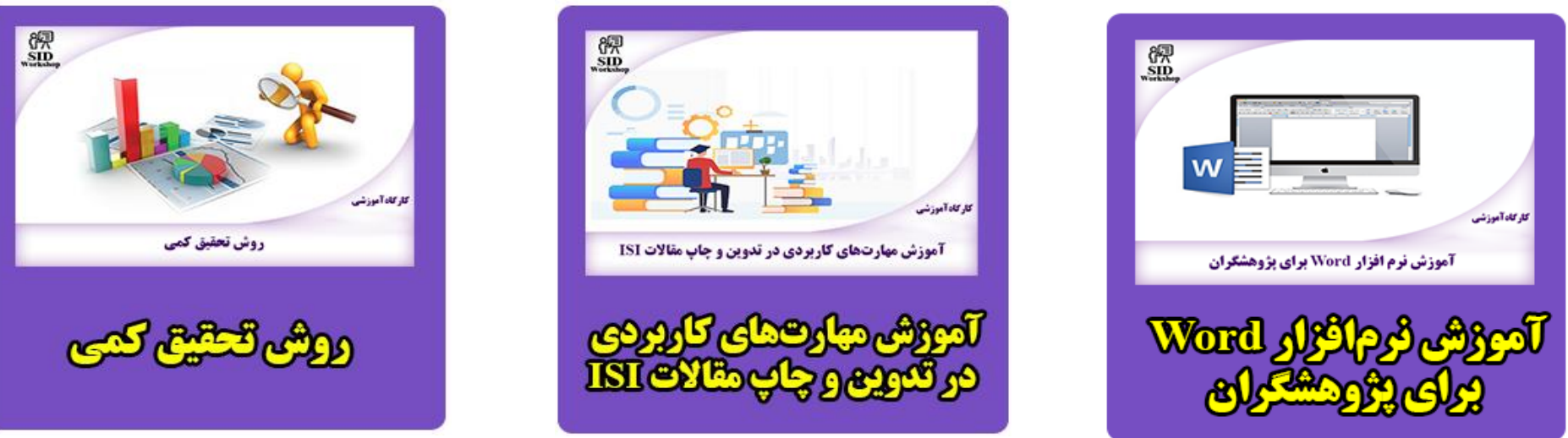